\title{
Different outcomes of pulmonary rehabilitation in patients with COPD with or without exacerbations
}

\author{
G.G. Riario-Sforza, C. Incorvaia, F. Paterniti, N. Dugnani, M. Fumagalli
}

ABSTRACT: Different outcomes of pulmonary rehabilitation in patients with COPD with or without exacerbations. G.G. Riario-Sforza, C. Incorvaia, F. Paterniti, N. Dugnani, M. Fumagalli.

Background. Pulmonary rehabilitation is recognised as an effective treatment in reducing disability and improving the quality of life in patients with COPD. We evaluated the effects of a course of pulmonary rehabilitation in improving the physical performance and lung function in patients with or without COPD exacerbations.

Methods. 74 patients with COPD were enrolled, 37 (24 males and 13 females, mean age $\mathbf{7 4 . 6}$ years) without exacerbations (group A), and 37 ( 23 males, 14 females, mean age 73.9 years) with exacerbations (group B). The latter must have had the latest exacerbation at least one month before the inclusion. All patients underwent to a rehabilitation programme of 8 visits in 4 weeks in a day-hospital setting, with exercise training, respiratory muscle training and education on COPD. The changes in physical perfor- mance and lung function in respect to baseline were measured by a 6-minute walking test, using phethysmography, and by an analogic manometer measuring maximal inspiratory and expiratory pressures (MIP, MEP).

Results. Patients of group A showed a mean increase in timed walk distance of $\mathbf{5 8 . 3 8} \pm \mathbf{5 7 . 4 6} \mathrm{m}$, compared to a mean increase of $31.38 \pm \mathbf{4 4 . 7 8} \mathrm{m}$ in group $B$ patients $(p=$ 0.028). As to lung function, a mean increase of $178.92 \pm$ $132.28 \mathrm{ml}$ in $\mathrm{FEV}_{1}$ in group $A$ versus $67.84 \pm 102.04 \mathrm{ml}$ in group $B(p<0.0001)$ and a mean increase of $22.36 \pm 25.06$ cm $\mathrm{H}_{2} \mathrm{O}$ in $\mathrm{MEP}$ in group $A$ versus $7.70 \pm 12.28 \mathrm{~cm} \mathrm{H}_{2} \mathrm{O}$ in group $B(p=0.002)$ was found.

Conclusions. These findings indicate that patients with COPD with exacerbations achieve a less favourable outcome of pulmonary rehabilitation, with a significantly lower improvement of physical performance, respiratory muscle strength and lung function in respect to subjects without exacerbations.

Monaldi Arch Chest Dis 2005; 63: 3, 129-132.

Keywords: COPD, pulmonary rehabilitation, exacerbations, 6-minute walking test, $\mathrm{MEP}, \mathrm{FEV} \mathrm{I}_{1}$.

Unit of Pulmonary Rehabilitation, ICP Hospital, via Bignami 1, Milan, Italy.

Correspondence: Cristoforo Incorvaia; Viale Molise 69, 20137 Milano, Italy; e-mail: cristoforo.incorvaia@fastwebnet.it

\section{Introduction}

Chronic Obstructive Pulmonary Disease (COPD) is a major health problem characterised by a progressive impairment of lung function [1] leading to inability and mortality, which is projected to increase its burden in the next years [2]. This makes the treatment strategies for COPD crucial. Currently, these are mainly stated in smoking cessation, drug therapy and pulmonary rehabilitation [3] with a recognised role for the latter in improving quality of life and reducing disability [4].

An important aspect of COPD are the exacerbations, which, though not yet generally accepted in their definition [5], clearly affect the course of the disease and require drug treatment with oral corticosteroids and antibiotics, as well as frequent hospitalisations. However, the influence of exacerbations on the response to pulmonary rehabilitation is scantly investigated. One study reported a change in exercise capacity lower than predicted in patients recovering from an acute exacerbation [6], but to our knowledge no comparative analysis of the outcome of pulmonary rehabilitation in patients with or without exacerbations in their clinical history is available.
We compared two groups of patients suffering from COPD, one group with exacerbations and the other without exacerbations, undergoing a standard programme of pulmonary rehabilitation, measuring as outcome parameters the physical performance as assessed by a walking test, the lung function as measured by plethysmographic tracing, and the respiratory muscle strength as measured by analogical manometry.

\section{Material and methods}

\section{Patients}

From patients with COPD referring to the Unit of Pulmonary Rehabilitation of the ICP Hospital in Milan, 37 subjects with a negative history for exacerbations (group A) and an equal number with a positive history for at least three exacerbations in the last three years (group B) were selected. No patient was previously treated with pulmonary rehabilitation. To include patients with exacerbations they must have had their latest episode at least one month before. This is the amount of time considered essential to recover functional stability [7]. A reversibility test was made to exclude patients with 
significant improvement of $\mathrm{FEV}_{1}$ after inhalation of salbutamol.

A number of characteristics potentially able to influence the results were considered. In all patients the duration of COPD, the smoking habit, the presence of concomitant cardiopathy, the use of inhaled beta2-agonists, and the use of inhaled corticosteroids were obtained by clinical history. The lung function at baseline was also considered, thus all patients underwent prior the start of rehabilitation programme, which averaged one month after the inclusion, to pneumologic assessment by plethysmography, measurement of maximum inspiratory and expiratory mouth pressures (MIP and MEP) as indicators of loss in respiratory muscle strength, and the 6-minute walking test as indicator of exercise performance [8], with an increase of at least 54 meters compared to baseline considered as significant [9].

During the rehabilitation programme no change to the drug treatment was made.

\section{Methods}

Functional assessment: The $\mathrm{FEV}_{1}$, the FVC, and the RV were measured by an automated pulmonary function testing center (6200 Autobox DL, Sensor Medics, Yorba Linda, CA, USA) in accordance with recognised standards [10]. MIP and MEP were gauged by an hand-held analogic manometer (PiMAX - PeMAX METER, Alpa, Milan, Italy) measuring from -200 to $+200 \mathrm{~cm}$ $\mathrm{H}_{2} \mathrm{O}$.

Six-minute walking test: The test was performed as previously described [8], following adequate instruction and training of each patient. The walking distance was measured by using a $37 \mathrm{me}-$ ter-long hospital corridor where the patients had to walk from end to end at their own pace while receiving verbal encouragement by a research assistant.

Pulmonary rehabilitation: The programme was conducted according to a schedule in eight visits in four weeks in a day hospital setting, with exercise training by either cycle ergometer or treadmill, according to the patient's capacity, for 30 minutes. Upper-limb and trunk exercise training, and respiratory muscle training carried out using low pressure PEP with a bottle at 6-8 $\mathrm{cm} \mathrm{H}_{2} \mathrm{O}$ and a tube 80 $\mathrm{cm}$ long with a $1 \mathrm{~cm}$ diameter. In addition, patients attended a standard educational course of eight lessons on COPD and were instructed to perform the muscle exercise and respiratory training each day at home for the duration of the programme.

\section{Statistical analysis}

Frequency distributions of the characteristics of the two groups at baseline and of the improvement in 6 minute walking test were compared using the chi-square test. The differences between the two groups with a $95 \%$ confidence interval in $\mathrm{FEV}_{1}$ and MEP measurement and in the timed walk distance were analysed by the T test, the correlation between different parameters were analysed by the Pearson test. A p value lower than 0.05 was considered significant.

\section{Results}

The two groups were well matched according to demography and the considered characteristics, as reported in table 1 . In particular, the mean baseline values of functional parameters and of timed walk distance were not significantly different. In group A - patients without exacerbations - 19 of 37 subjects had a significant improvement at the 6minute walking test, with a walking distance at least 54 meters longer than the baseline, while in the group B - patients with exacerbations - 12 of 37 subjects achieved such outcome, this distribution being not significantly different. The mean changes in FVC, RV, and MIP were not significantly different between the two groups, while the mean changes in timed walk distance, $\mathrm{FEV}_{1}$, and MEP, demonstrated a significant difference in favour of the group without exacerbations $(\mathrm{p}=$ 0.028 for timed walk distance, $\mathrm{p}<0.0001$ for $\mathrm{FEV}_{1}$, and $\mathrm{p}=0.002$ for MEP with the T test), as shown in table 2 . The values of the two functional parameters were significantly correlated both at baseline and after pulmonary rehabilitation ( $\mathrm{p}<$ 0.001 with Pearson test), while no significant correlation was found between their improvement and the results of the 6-minute walking test.

\section{Discussion}

Pulmonary rehabilitation is a treatment of established effectiveness in COPD, as clearly demonstrated by meta-analysis of the available

Table 1. - Demography and characteristics of the two groups, group A (without exacerbations) and group B (with exacerbations)

\begin{tabular}{|c|c|c|c|c|c|c|c|c|c|c|c|c|}
\hline Group & Gender & $\begin{array}{l}\text { Age } \\
\text { (yrs) }\end{array}$ & $\begin{array}{c}\text { COPD } \\
\text { duration } \\
<5 \text { yrs }\end{array}$ & $\begin{array}{l}\text { Smoking } \\
\text { history }\end{array}$ & Cardiopathy & $\begin{array}{c}\text { 0n } \\
\text { beta2- } \\
\text { agonists }\end{array}$ & $\begin{array}{c}\text { On inhaled } \\
\text { corticosteroids }\end{array}$ & $\begin{array}{c}\text { MIP in cm } \\
\mathrm{H}_{2} \mathrm{O} \\
\text { (\% predicted) }\end{array}$ & $\begin{array}{c}\text { MEP in cm } \\
\mathrm{H}_{2} \mathrm{O} \\
\text { (\% predicted) }\end{array}$ & $\mathrm{FEV}_{1}$ in $\mathrm{ml}$ & $\mathrm{FVC} \mathrm{in} \mathrm{ml}$ & $\mathrm{RV}$ in $\mathrm{ml}$ \\
\hline A & $\begin{array}{l}24 \mathrm{~m} \\
13 \mathrm{f}\end{array}$ & $\begin{array}{c}74.6 \\
(61-84)\end{array}$ & $16 / 37$ & $31 / 37$ & $2 / 37$ & $20 / 37$ & $27 / 37$ & $\begin{array}{c}82.14 \pm 25.36 \\
(93.76 \pm 29.01)\end{array}$ & $\begin{array}{c}90.86 \pm 33.42 \\
(54.78 \pm 21.97)\end{array}$ & $1249.9 \pm 673.3$ & $2533.4 \pm 648.9$ & $3329.1 \pm 1289.3$ \\
\hline B & $\begin{array}{l}23 \mathrm{~m} \\
14 \mathrm{f}\end{array}$ & $\begin{array}{c}73.9 \\
(56-85)\end{array}$ & $25 / 37$ & $29 / 37$ & $4 / 37$ & $23 / 37$ & $30 / 37$ & $\begin{array}{c}77.50 \pm 26.69 \\
(92.54 \pm 22.85)\end{array}$ & $\begin{array}{c}88.33 \pm 41.61 \\
(53.11 \pm 16.57)\end{array}$ & $1191.6 \pm 584.9$ & $2212.7 \pm 803.1$ & $3390.6 \pm 1605.5$ \\
\hline
\end{tabular}


Table 2. - Results of walking distance, $\mathrm{FEV}_{1}$, and MEP measurement before and after pulmonary rehabilitation $(\mathrm{PR})$ in the two groups, group A (without exacerbations) and group $B$ (with exacerbations)

\begin{tabular}{|c|c|c|c|c|c|c|c|c|c|c|c|c|}
\hline \multirow[t]{2}{*}{ Group } & \multicolumn{4}{|c|}{ Timed walking distance (metres) } & \multicolumn{4}{|c|}{$\mathrm{FEV}_{1}(\mathrm{ml})$} & \multicolumn{4}{|c|}{$\operatorname{MEP}\left(\mathrm{cm} \mathrm{H}_{2} \mathrm{O}\right)$} \\
\hline & Before PR & After PR & $\begin{array}{c}\text { Mean } \\
\text { difference } \\
\text { between groups }\end{array}$ & $\begin{array}{l}95 \% \text { C.I. } \\
\text { significance } \\
\text { (p) }\end{array}$ & Before PR & After PR & $\begin{array}{c}\text { Mean } \\
\text { difference } \\
\text { between groups }\end{array}$ & $\begin{array}{l}95 \% \text { C. I. and } \\
\text { significance } \\
\text { (p) }\end{array}$ & Before PR & After PR & $\begin{array}{c}\text { Mean } \\
\text { difference } \\
\text { between groups }\end{array}$ & $\begin{array}{l}95 \% \text { C. I and } \\
\text { significance } \\
\text { (p) }\end{array}$ \\
\hline A & $386.7 \pm 124.6$ & $445.1 \pm 143.2$ & $58.38 \pm 57.46$ & $\begin{array}{c}3.13-50.87 \\
0.028\end{array}$ & $1249.9 \pm 673.3$ & $1428.9 \pm 711.4$ & $178.92 \pm 132.28$ & $\begin{array}{c}56.33-165.83 \\
<0.0001\end{array}$ & $90.86 \pm 33.42$ & $113.32 \pm 42.334$ & $22.36 \pm 25.06$ & $\begin{array}{c}5.49-23.93 \\
0.002\end{array}$ \\
\hline B & $369.3 \pm 118.4$ & $400.7 \pm 132.5$ & $31.38 \pm 44.78$ & & $1191.6 \pm 584.9$ & $1259.4 \pm 615.6$ & $67.84 \pm 102.04$ & & $88.33 \pm 41.61$ & $96.03 \pm 38.16$ & $7.70 \pm 12.28$ & \\
\hline
\end{tabular}

studies [11]. It is generally composed by physical activity and education, and the improvement of patients may be assessed in a number of outcomes, including quality of life, symptoms, physical performance, and number and duration of hospitalisation caused by COPD $[12,13]$. Regarding physical performance, the 6 minute walking test was demonstrated as an adequate index to measure the exercise capacity after an initial course of pulmonary rehabilitation [14], and the cut-off indicating a significant improvement was established in an increase of 54 metres in respect of the baseline value [9].

By contrast, thus far there is no data indicating that pulmonary rehabilitation is able to improve lung function. On the other hand, it has long been thought that in COPD the progressive decrease of lung function, as expressed by measurement of $\mathrm{FEV}_{1}$ cannot be prevented by any treatment [15].

However, recent studies have demonstrated that drug treatment, and in particular latest generation inhaled corticosteroids and long acting beta2agonists, are able to obtain significant improvement in the $\mathrm{FEV}_{1}$ measurement [16], and therefore such concepts must be considered no more a postulate.

The aim of the present study was to compare the changes observed in the 6 minute walking test as an index of physical ability and in the $\mathrm{FEV}_{1}$ as an index of lung function after an initial course of pulmonary rehabilitation in patients with COPD with or without exacerbations. The most recent definition describes an exacerbation as "a sustained worsening of the patient's symptoms from his or her usual stable state that is beyond normal day to day variation, and is acute in onset. The change in symptoms often necessitates a change in medication" [17]. We allocated the patients in the group with exacerbation when they had had at least three exacerbations in the last three years, with the latest exacerbation occurring at least one month before inclusion - and actually about two months before commencing rehabilitation - to avoid clinical instability due to a recent episode. In fact, the two groups were well matched regarding demographic data, characteristics of COPD, and functional parameters at baseline. No significant difference between the groups in the number of subjects significantly improving at walking test, with at least 54 metres more than baseline, was observed. Howev- er, statistical analysis detected an highly significant difference in the mean number of meters walked compared to baseline in favour of the group of patients without exacerbations. Also, a highly significant difference was found concerning the improvement of the $\mathrm{FEV}_{1}$ and of MEP in patients without exacerbations compared to patients with exacerbations. The two parameters were statistically correlated, suggesting a probable role of respiratory muscle training, which achieved a significantly higher increase of the muscle strength in patients without exacerbations and consequently improved their ability in performing expiratory manoeuvres. By contrast, the significantly higher improvement in the timed walking distance in patients without exacerbations, statistically unrelated to the functional parameters, is likely to depend upon the general exercise training. Nonetheless, the overall results indicate a more favourable outcome in subjects without exacerbations, at least with the rehabilitation protocol we used in this study.

Of course, this does not mean that patients with exacerbations are not responsive to pulmonary rehabilitation. For example, it has been reported that in patients with exacerbations a course of pulmonary rehabilitation is able to reduce their frequency and duration in the follow-up [4]. Moreover, also in the group we studied a substantial number of subjects with exacerbations showed an improvement of the physical performance as measured by the walking test, despite the fact that they failed to improve the MEP and $\mathrm{FEV}_{1}$.

These findings should stimulate research in the pathophysiology of exacerbations, on which little is currently known [15], and especially on the factors underlying their occurrence or not in COPD patients, with particular attention at changes of the functional parameters.

\section{References}

1. Barnes PJ. Chronic obstructive pulmonary disease. $N$ Engl J Med 2000; 343: 269-80.

2. Murray CJ, Lopez AD. Alternative projection of mortality by cause 1990-2020: global burden of disease study. Lancet 1997; 349: 1498-504.

3. Sutherland ER, Cherniak RM. Management of chronic obstructive pulmonary disease. N Engl J Med 2004; 350: 2689-97.

4. British Thoracic Society. Pulmonary rehabilitation. Thorax 2001; 56: 827-34. 
5. Pauwels R, Calverley P, Buist AS, et al. COPD exacerbations: the importance of a standard definition. Respir Med 2004; 98: 99-107.

6. Cilione C, Lorenzi C, Dell'Orso D, et al. Predictors of change in exercise capacity after comprehensive COPD impatient rehabilitation. Med Sci Monit 2002; 8: 740-5.

7. Donaldson GC, Seemungal TAR, Bhowmik A, Wedzicha JA. Relationship between exacerbations frequency and lung function decline in chronic obstructive lung disease. Thorax 2002; 57: 847-52.

8. Guyatt GH, Sullivan MJ, Thompson PJ, et al. The 6-minute walk: a new measure of exercise capacity in patients with chronic heart failure. Can Med Assoc J 1985; 132: 919-23.

9. Redelmeier DA, Bayoumi A, Goldstein RS, Guyatt GH. Interpreting small differences in functional status: the six minute walk test in chronic lung disease patients. Am J Respir Crit Care Med 1997; 155: 1278-82.

10. American Thoracic Society. Standardization of spirometry: 1994 update. Am J Respir Crit Care Med 1995; 152: 1107-36.

11. Lacasse Y, Brosseau L, Milne S. Pulmonary rehabilitation for chronic obstructive pulmonary disease (Cochrane review). Cochrane Library, issue 3 (Oxford: update software). 2002.
12. Ries AL, Kaplan RM, Limberg TM, Prewitt LM. Effects of pulmonary rehabilitation on physiologic and psychosocial outcomes in chronic obstructive pulmonary disease. Ann Intern Med 1995; 122: 823-32.

13. Celli BR. Pulmonary rehabilitation in patients with COPD. Am J Respir Crit Care Med 1995; 152: 861-4.

14. Votto J, Bowen J, Scalise P, Wollschlagen C, Zu Wallack R. Short-stay comprehensive inpatient pulmonary rehabilitation for advanced chronic obstructive pulmonary disease. Arch Phys Med Rehabil 1996; 77: 1115-8.

15. Global Initiative for Chronic Obstructive Lung Disease (GOLD). Global strategy for the diagnosis, management and prevention of chronic obstructive pulmonary disease. NHLB/WHO workshop report, NIH publication 2701. Bethesda, US Department of Health and $\mathrm{Hu}-$ man Services, 2001.

16. Calverley P, Pauwels R, Vestbo J, et al. Combined salmeterol and fluticasone in the treatment of chronic obstructive pulmonary disease: a randomised controlled trial. Lancet 2003; 361: 449-56.

17. National clinical guidelines on management of chronic obstructive pulmonary disease in adults in primary and secondary care. Thorax 2004; 59 (suppl 1): 1-232.

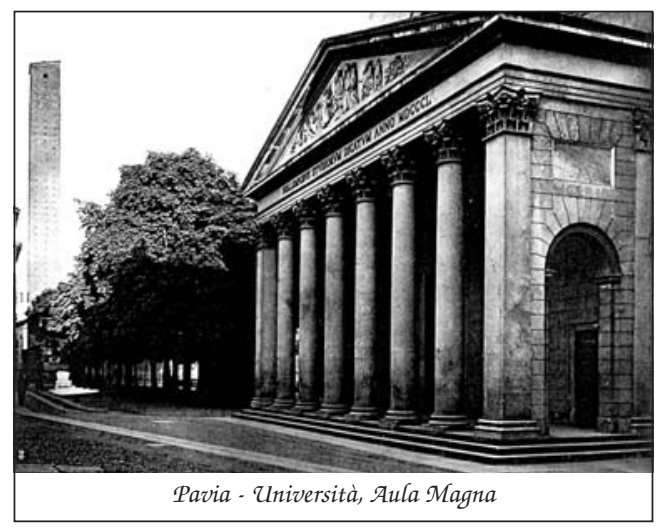

